\title{
Sequence divergence of microsatellites for phylogeographic assessment of Moroccan Medicago species
}

\author{
N. Zitouna ${ }^{1}$, S. Marghali ${ }^{1}$, M. Gharbi ${ }^{1}$, A. Haddioui ${ }^{2}$ and N. Trifi-Farah ${ }^{1}$ \\ ${ }^{1}$ Laboratory of Molecular Genetics, Immunology, and Biotechnology, \\ Faculty of Sciences, University of Tunis El Manar, Campus Universitaire, \\ Tunis, Tunisia \\ ${ }^{2}$ Laboratory of Plant Genetics and Biotechnology, \\ Faculty of Sciences and Technology, \\ University of Sultan Moulay Slimane, Beni-Mellal, Morocco \\ Corresponding author: N. Trifi-Farah \\ E-mail: neila.trifi@fst.rnu.tn
}

Genet. Mol. Res. 13 (1): 1548-1562 (2014)

Received December 21, 2012

Accepted June 28, 2013

Published March 12, 2014

DOI http://dx.doi.org/10.4238/2014.March.12.7

\begin{abstract}
Six Medicago species were investigated to characterize and valorize plant genetic resources of pastoral interest in Morocco. Samples were obtained from the core collection of the South Australian Research and Development Institute (SARDI). The transferability of single sequence repeat markers of Medicago truncatula was successful with $97.6 \%$ efficiency across the five species. A total of 283 alleles and 243 genotypes were generated using seven SSR markers, confirming the high level of polymorphism that is characteristic of the Medicago genus, despite a heterozygosity deficit $\left(H_{\mathrm{O}}=0.378 ; H_{\mathrm{E}}=0.705\right)$. In addition, a high level of gene flow was revealed among the species analyzed with significant intra-specific variation. The unweighted pair group method with arithmetic mean dendrogram generated by the dissimilarity matrix revealed that $M$. polymorpha and $M$. orbicularis are closely related, and that $M$. truncatula is likely the ancestral species.
\end{abstract}


The Pearson correlation index revealed no significant correlations between the geographic distribution of the Moroccan species and genetic similarities, indicating local adaptation of these species to different ecological environments independent of their topographical proximities. The substantial genetic variation observed was likely due to the predominance of selfing species, the relative proximity of prospected sites, human impacts, and the nature of the SARDI core collections, which are selected for their high genetic diversity. The results of this first report on Moroccan Medicago species will be of great interest for establishing strategies aiming at reasonable management and selection programs for local and Mediterranean germplasm in the face of increasing environmental change.

Key words: Medicago; Simple sequence repeat; Transferability; Genetic diversity; Geographic distribution; Phylogeny

\section{INTRODUCTION}

The Fabaceae, also called Leguminosae, is the third largest family of Angiosperms in terms of agricultural and economical importance. It includes more than 650 genera and 20,000 species, with a large number of domesticated species harvested as crops for human and animal consumption, as well as for oils, fuel, fertilizers, and medicinal and horticultural varieties (Lewis et al., 2005). Belonging to the tribe Trifolieae (Fabaceae) and the subtribe Trigonellinae, Medicago is an extensive genus comprising more than 83 different species and 18 intraspecific taxa of flowering plants, which are annuals (66\%) or perennials (33\%). Annual species of Medicago, commonly known as medics, are currently found in flora bordering or close to the northern coast of the Mediterranean Sea, the Arabian Peninsula, Iraq, and the eastern Balkans. However, many of these species are endemic to restricted subsets of these areas (Lesins and Lesins, 1979; Maureira-Butler et al., 2008; Yousfi et al., 2010). Medics combine traits such as vigorous seedling growth and cold tolerance with high forage quality, prolific seed production, resistance to pests, and high morphological diversity. They are considered as potential species for pasture improvement in Mediterranean regions (Yousfi et al., 2010).

Medicago truncatula Gaertn originated from the Mediterranean area is used as stock feed in leys or permanent pastures of the subtropical areas of Australia and the United States of America. The genome size of this autogamous, diploid, annual plant is approximately 470 $\mathrm{Mb}$, which is three times larger than that of Arabidopsis thaliana $(125 \mathrm{Mb})$. M. truncatula is considered to be very closely related to legumes of Fabaceae genera, and was selected as a model legume species that would serve as reference for all Fabaceae species (Sanders et al., 2011).

In the Mediterranean basin, Medicago species are currently threatened by severe reductions in number and size due to rapid urbanization and irregular precipitation patterns (Birouk, 1993). Therefore, it is imperative to promote and conserve these phytogenetic resources in order to provide alternative approaches toward the valorization and promotion of these important forage crops in order to introduce them to fallow and marginal pastoral zones. The evaluation of the genetic diversity among populations is an essential prerequisite for the preservation of endangered species (Park et al., 2009). To improve the conservation of these 
species, morphological and isoenzyme markers have so far been used to characterize Medicago species in Morocco (Birouk, 1993; Haddioui et al., 2012).

Because molecular markers show Mendelian inheritance, it is possible to trace the fingerprint of each individual and determine the evolutionary history of the species by phylogenetic analysis and population genetic structures (Hoshino et al., 2012). Molecular analysis of germplasm diversity will provide information for use in plant improvement programs regarding the level of genetic variation within and between species. This information could then be used for interspecific crosses, to increase heterozygosity, and to incorporate desirable genes from more diverse backgrounds into elite germplasm (Phansak et al., 2005).

Microsatellite markers, known to be ubiquitous in eukaryotic genomes, are thought to play an active role in genome evolution by creating and maintaining genetic variability due to their high mutability, which can be exploited in conservation and improvements of forage production (Jayashree et al., 2006).

Simple sequence repeats (SSRs) are short stretches of DNA sequences occurring as tandem repeats of mono-, di-, tri-, tetra-, penta-, and hexa-nucleotides in both protein coding and non-coding regions of DNA sequences (Toth et al., 2000; Lai et al., 2012). The polymorphism in microsatellite sequences consists of variation in the length of the repeated motif, and can be easily detected using a polymerase chain reaction (PCR)-based technique with primers flanking the SSR motif (Phansak et al., 2005). Compared to other molecular markers, SSRs are characterized as simple, abundant markers, and by their cost-effective deployment. Their broad utility has been revealed in phylogenetic and phylogeographic analyses in plant species (Powell et al., 1996; Varshney et al., 2005). SSRs are also locus-specific, thereby facilitating the use of these codominant markers for comparative mapping studies (Varshney et al., 2005). Among the legumes, the availability of SSRs is limited to species for which sequencing databases already exist. The legume model $M$. truncatula, exhibiting genetic proximity with Fabaceae genera, offers the potential to easily transfer information about its genome structure onto other legume crops (Gutierrez et al., 2005).

In this context, the close association between M. truncatula genome and that of five other Medicago species was exploited in the present study. The identified M. truncatula SSR markers were used to quantify i) the transferability of $M$. truncatula SSR markers, ii) the neutral genetic diversity at both intra- and interspecific levels, and iii) the relationships among the six Moroccan species, M. truncatula, M. minima, M. orbicularis, M. scutellata, M. polymorpha, and M. murex.

\section{MATERIAL AND METHODS}

\section{Geographic distribution of the plant material}

The diploid Medicago species (M. truncatula, M. scutellata, M. minima, and M. orbicularis), characterized by $2 \mathrm{n}=16$, and M. polymorpha and $M$. murex $(2 \mathrm{n}=14)$ were provided by the core collection of the Genetic Resource Centre of the South Australian Research and Development Institute (SARDI), representing specimens collected from different Moroccan provinces. This core collection consists of sub-samples of populations chosen to represent the majority of the genetic diversity contained in a larger collection. The latitude, longitude, and altitude of each species' collection location are listed in Table 1. 
Table 1. Spatial repartition of the six Moroccan species of Medicago provided from the SARDI core collection.

\begin{tabular}{lcccc}
\hline Species & Accession's code & Latitude & Longitude & Altitude $(\mathrm{m})$ \\
\hline M. scutellata & SA29511 & $32^{\circ} 60^{\prime}$ & $6^{\circ} 35^{\prime}$ & 1100 \\
M. murex & SA25862 & $33^{\circ} 21^{\prime}$ & $6^{\circ} 30^{\prime}$ & 800 \\
M. truncatula & SA10406 & $33^{\circ} 00^{\prime}$ & $6^{\circ} 00^{\prime}$ & 790 \\
M. polymorpha & SA32297 & $33^{\circ} 00^{\prime}$ & $5^{\circ} 45^{\prime}$ & 1000 \\
M. minima & SA29446 & $32^{\circ} 06^{\prime}$ & $6^{\circ} 35^{\prime}$ & 1800 \\
M. orbicularis & SA29544 & $32^{\circ} 50^{\prime}$ & $5^{\circ} 54^{\prime}$ & 800 \\
\hline
\end{tabular}

\section{Germination}

Ten randomly collected seeds from each species were scarified and soaked in water for $48 \mathrm{~h}$. Seeds were then transferred to Petri dishes on moist blotting paper and exposed to light until the emergence of roots and cotyledons. When the radicle was $4-5 \mathrm{~cm}$ in length, DNA was isolated.

\section{DNA isolation}

Genomic DNA was extracted from individual seedlings with the Pure Link DNA Extraction and Purification kit (Invitrogen, France) following manufacturer instructions. DNA quality was assessed on $0.8 \%$ agarose gel stained with ethidium bromide, and visualized under UV-light. Quantification was then carried out using a Gene-Quant spectrophotometer (Pharmacia), and samples were stored at $-20^{\circ} \mathrm{C}$.

\section{PCR amplification and SSR fingerprinting}

To efficiently exploit the variation in the SARDI collection, a set of seven M. truncatula SSR primers, designed by Huguet $\mathrm{T}$ (unpublished data), were tested among the six considered species (Table 2). Each $25-\mu \mathrm{L}$ PCR mixture contained 30 ng template genomic DNA, $100 \mathrm{mM}$ dNTP, $2 \mathrm{mM} \mathrm{MgCl}, 2.5 \mu \mathrm{L}$ 10X Taq buffer, $2 \mathrm{U}$ Taq DNA polymerase (Invitrogen), $50 \mathrm{ng} / \mu \mathrm{L}$ of each forward and reverse primer, and distilled water. The touchdown PCR amplification profile had an initial denaturation step for $4 \mathrm{~min}$ at $94^{\circ} \mathrm{C}$, followed by 35 cycles of $30 \mathrm{~s}$ at $94^{\circ} \mathrm{C}, 45 \mathrm{~s}$ at the annealing temperature (depending on the locus), and $60 \mathrm{~s}$ at $72^{\circ} \mathrm{C}$, with a final extension at $72^{\circ} \mathrm{C}$ for $4 \mathrm{~min}$. PCR was carried out in a TC512-TECHNE thermal controller. The amplified banding patterns were first checked on $1.5 \%$ agarose gels stained with ethidium bromide. The molecular size of each fragment was approximately estimated using the Invitrogen 100-bp DNA ladder as a standard. PCR products were then applied to a 1-K DNA LabChip, and were detected with the Experion automated capillary electrophoresis system (Biorad, Hercules, CA, USA). All gels, electrophoregrams, and the concentration areas of each peak were reported using the Experion System Operation software and Data Analysis Tools (version 1.0).

\section{Statistical analysis}

The clearly distinguishable amplified bands were scored as genotypes according to the molecular weight of alleles. As all species analyzed are diploids $(2 n=14$ or 16$)$, individuals are represented by one allele (for the homozygotes) or two alleles (for the heterozygotes). Null alleles were recorded as 0 . 


\begin{tabular}{|c|c|c|c|c|}
\hline Primer code & Sequence $\left(5^{\prime}-3^{\prime}\right)$ & Amplicon $\left[\operatorname{Tm}\left({ }^{\circ} \mathrm{C}\right)\right]$ & Size range & Repeated motif \\
\hline MTIC138 & $\begin{array}{l}\text { F: CCAGACCACAAGAAATTCCAC } \\
\text { R: ATGGTTTCTGAGCAGCTGGA }\end{array}$ & 50 & $234-382$ & {$[\mathrm{ATT}]_{5}$} \\
\hline MTIC160 & $\begin{array}{l}\text { F: GAGGGGAGCACCTCAAAGTT } \\
\text { R: GTATCTGCCGGTGGGAAGT }\end{array}$ & 50 & $137-238$ & {$[\mathrm{AG}]_{5}$} \\
\hline MTIC338 & $\begin{array}{l}\text { F: TCCCCTTAAGCTTCACTCTTTTC } \\
\text { R: CATTGGTGGACGAGGTCTCT }\end{array}$ & 48 & $93-195$ & {$[\mathrm{CTT}]_{5}$} \\
\hline MTIC354 & $\begin{array}{l}\text { F: AAGTGCCAAAGAACAGGGTTT } \\
\text { R: AACCTACGCTAGGGTTGCAG }\end{array}$ & 50 & $102-155$ & {$[\mathrm{TGG}]_{7}$} \\
\hline MTIC375 & $\begin{array}{l}\text { F: ATGCTCGCCGTAAGACTGTT } \\
\text { R: GAGCTCAAGTGCGGTTACAA }\end{array}$ & 48 & $74-126$ & {$[\mathrm{AT}]_{5}$} \\
\hline MTIC470 & $\begin{array}{l}\text { F: GGTTCGTGTATTTGTTCGAT } \\
\text { R: CCCTTCACAGAATGATTGAT }\end{array}$ & 55 & $114-164$ & {$[\mathrm{TG}]_{10}$} \\
\hline MTIC27 & $\begin{array}{l}\text { F: CGATCGGAACGAGGACTTTA } \\
\text { R: CCCCGTTTTTCTTCTCTCCT }\end{array}$ & 48 & $144-248$ & {$[\mathrm{AAG}]_{6}$} \\
\hline
\end{tabular}

Primers were designed by Huguet $\mathrm{T}$ (unpublished data).

Following the numerically coded data format required by the GenAlEX6 software (Peakall and Smouse, 2006), SSR data were presented as two columns per locus. Molecular diversity was scored for each species according to the following parameters: 1) number of observed alleles $\left.\left(N_{\mathrm{A}}\right), 2\right)$ the ratio of effective alleles $\left.\left(N_{\mathrm{E}}\right), 3\right)$ observed genotypes $\left.\left(N G_{\mathrm{A}}\right), 4\right)$ expected genotypes $\left.\left(N G_{\mathrm{E}}\right), 5\right)$ the fixation index $\left.(F), 6\right)$ the observed $\left(H_{\mathrm{O}}\right)$ and expected heterozygosities $\left(H_{\mathrm{E}}\right)$, and 7$)$ the percentage of polymorphic loci $(P)$. Wright's indices $\left(F_{\mathrm{ST}}, F_{\mathrm{IT}}\right.$, and $\left.F_{\text {IS }}\right), F$, and the Shannon-Weaver diversity index $(I)$ were calculated per locus. The matrix of similarities was obtained based on the Nei (1972) formula. The gene flow estimate, based on the $N_{\mathrm{M}}$ pairwise matrix, was computed using the Genetix software 4.5 (Belkhir et al., 2002). Geographic Distance Matrix Generator version 1.2.3 (Ersts, 2010) was used to generate a geographic distance matrix between pairs of species. The genetic identity matrix was used for hierarchical clustering analysis with the unweighted pair-group method with the arithmetic average (UPGMA) to demonstrate genetic relationships among the six Moroccan Medicago species using the MEGA program, version 5 (Tamura et al., 2011). Correlations between genetic similarities and geographic distance were estimated according to the Mantel test in the XLStat software (www.xlstat.com).

\section{RESULTS AND DISCUSSION}

A total of seven primers were screened for their ability to generate consistently amplified patterns and to reveal polymorphisms among the six Medicago species analyzed. The SARDI core collection is highly polymorphic, exhibiting 283 polymorphic markers with an average of $40.428 \mathrm{bp}$, ranging from 74 to $283 \mathrm{bp}$. Alleles were visualized using the Experion software, revealing electropherograms and concentration areas as illustrated in Figure 1.

\section{Transferability of M. truncatula SSRs to other medic species}

The length variations of SSR sequences result from insertions/deletions (In/Dels), and single nucleotide polymorphisms (SNPs) within the microsatellite motif/repeat region, or in sequences flanking the repeat regions (Calonje et al., 2008). SSRs demonstrate a high degree of transferability between species, as PCR primers designed for a specific genus frequently 
amplify a corresponding locus in related species, enabling comparative genetic and genomic analyses (Lai et al., 2012).

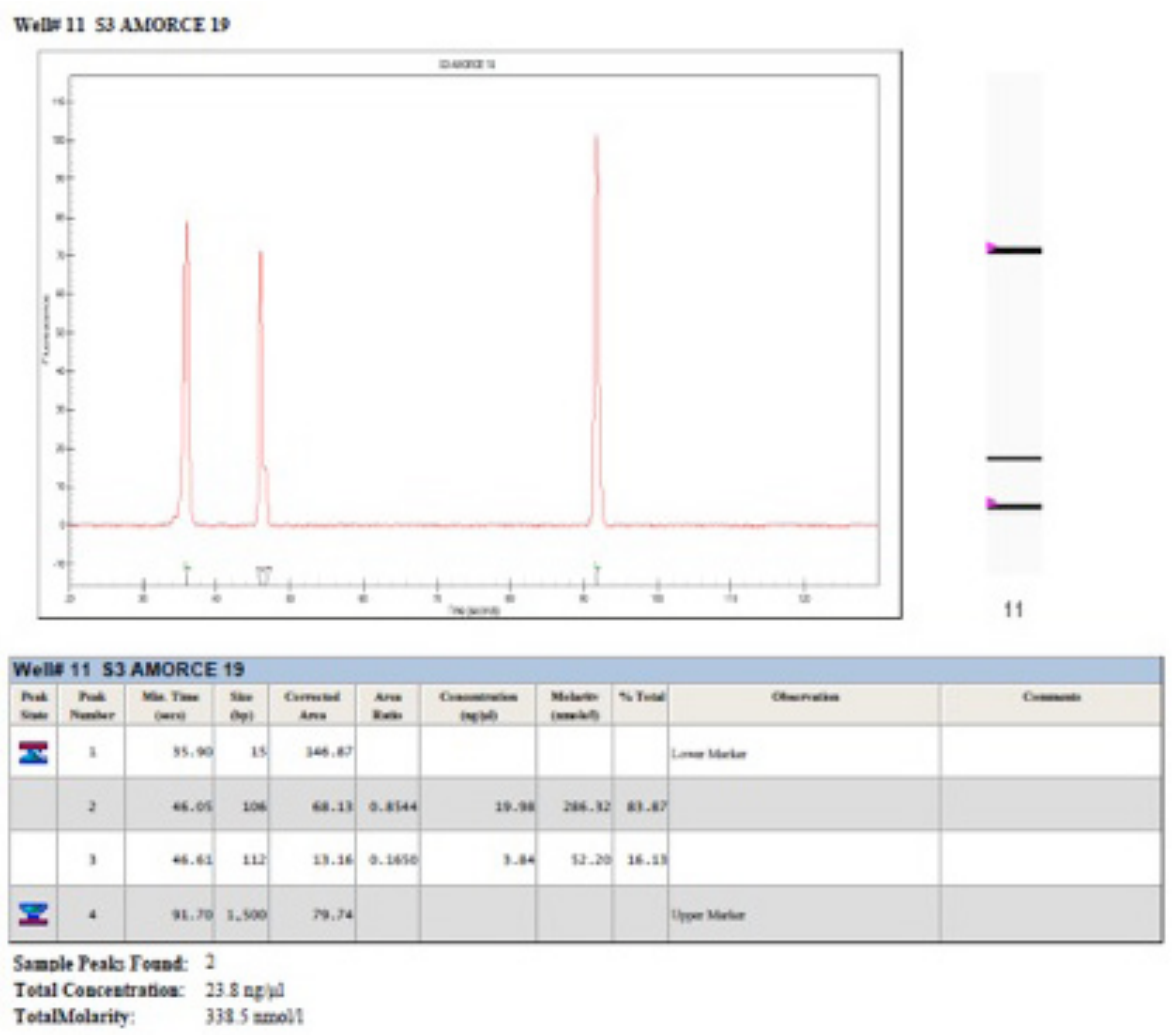

Figure 1. Example of PCR amplification' fingerprint using the EXPERION software (electropherogram, virtual gel and table of concentration).

In order to determine the potential for cross-species amplification, primer pairs of seven mapped M. truncatula SSR markers were tested in five related Medicago species $(M$. orbicularis, M. polymorpha, M. minima, M. murex, and M. scutellata) under the same PCR conditions. The transferability was revealed to be almost perfect with $97.6 \%$ efficiency. In fact, only M. minima did not amplify with the MTIC470 primer. Among the transferable SSRs, the size of the alleles did not differ between M. truncatula and the other species, except for MTIC354, for which the predicted size is $250 \mathrm{bp}$ for M. truncatula, and the generated alleles for the five other species ranged from 284 to $382 \mathrm{bp}$.

These results are in agreement with other studies using SSR cross-species amplification between legume genera or species. In fact, Yan et al. (2009) reported a 100\% rate of transferability of $M$. truncatula SSRs with two related species, M. lupulina and M. ruthenica. A high level (81.1\%) of cross-amplification was also detected in several Medicago species using expressed sequence tag (EST) SSRs from M. truncatula (Julier et al., 2003; Eujayl et al., 2004). Gutierrez et al. (2005) revealed significant transferability of $M$. truncatula microsatellites to the three pulses ( $40 \%$ in fava bean, $36.3 \%$ in chickpea, and $37.6 \%$ in pea). The extent 
of transferability of the M. truncatula EST database, which ranges from 40.6 to $32.3 \%$, has been demonstrated in fodder legumes such as Trifolium alexandrinum, Clitoria ternatea, Stylosanthes sp, Macroptelium atropurpureum, Desmanthus virgatus, Cyamopsis tetragonoloba, Lablab purpureus, Lathyrus sativus, Vicia narbonensis, and Melilotus parviflora (Chandra, 2011). Wang et al. (2004) reported 30.8\% successful cross-genus amplification between Medicago, soybean, cowpea, and peanut SSR markers across the legume family.

\section{Allele and genotype numbers and frequencies}

Surveying a core collection of Morrocan species with a set of seven microsatellite loci distributed throughout the genome, we revealed a large amount of genetic variability in Medicago species. In fact, a total of 243 different alleles and 283 genotypes were identified. This result was expected considering the power of the microsatellite markers to display high mutation rates, which generally reveal fairly high amounts of polymorphisms, especially when used at the species level (Ronfort et al., 2006).

The allele and genotype distributions per locus and per species are reported in Table 3. The most polymorphic locus was MTIC338, and the least was MTIC354, with 54 and 22 alleles, respectively. M. scutellata was the most polymorphic species with 56 alleles. Genetic variation comparison among the six species revealed the highest level of polymorphism in $M$. scutellata with the primer MTIC138 (13 alleles), while the lowest ( 2 alleles) was obtained for M. polymorpha based on the MTIC354 locus. Among M. polymorpha, two unequally distributed alleles, 365 and $360 \mathrm{bp}$, were observed; with frequencies of 0.95 (for the allele $365 \mathrm{bp}$ ) and 0.05 (for the allele $360 \mathrm{bp}$ ). Two sector diagrams are represented in Figure 2, illustrating the proportion of alleles generated for $M$. scutellata and M. polymorpha, respectively.

\begin{tabular}{|c|c|c|c|c|c|c|c|}
\hline & M. orbicularis & M. polymorpha & M. minima & M. scutellata & M. murex & M. truncatula & Total \\
\hline \multicolumn{8}{|c|}{ MTIC354 } \\
\hline NA & 4 & 2 & 4 & 8 & 2 & 2 & 22 \\
\hline NG & 4 & 2 & 4 & 6 & 2 & 1 & 19 \\
\hline \multicolumn{8}{|c|}{ MTIC338 } \\
\hline NA & 9 & 9 & 8 & 10 & 13 & 5 & 54 \\
\hline NG & 7 & 8 & 8 & 7 & 10 & 5 & 45 \\
\hline \multicolumn{8}{|c|}{ MTIC138 } \\
\hline NA & 12 & 7 & 5 & 13 & 7 & 7 & 51 \\
\hline NG & 8 & 6 & 4 & 10 & 6 & 6 & 40 \\
\hline \multicolumn{8}{|c|}{ MTIC160 } \\
\hline NA & 10 & 7 & 11 & 5 & 3 & 6 & 42 \\
\hline NG & 9 & 7 & 9 & 5 & 3 & 6 & 39 \\
\hline \multicolumn{8}{|c|}{ MTIC27 } \\
\hline NA & 5 & 7 & 9 & 7 & 4 & 7 & 39 \\
\hline NG & 5 & 7 & 9 & 5 & 3 & 7 & 36 \\
\hline \multicolumn{8}{|c|}{ MTIC470 } \\
\hline NA & 7 & 2 & 0 & 8 & 3 & 9 & 29 \\
\hline NG & 7 & 2 & 0 & 5 & 3 & 8 & 25 \\
\hline \multicolumn{8}{|c|}{ MTIC375 } \\
\hline NA & 6 & 8 & 9 & 5 & 10 & 8 & 46 \\
\hline NG & 6 & 7 & 8 & 5 & 7 & 6 & 39 \\
\hline \multicolumn{8}{|l|}{ Total } \\
\hline NA & 53 & 42 & 46 & 56 & 42 & 44 & 283 \\
\hline NG & 46 & 39 & 42 & 43 & 34 & 39 & 243 \\
\hline
\end{tabular}

$\mathrm{NA}=$ number of alleles; $\mathrm{NG}=$ number of genotypes. 
A

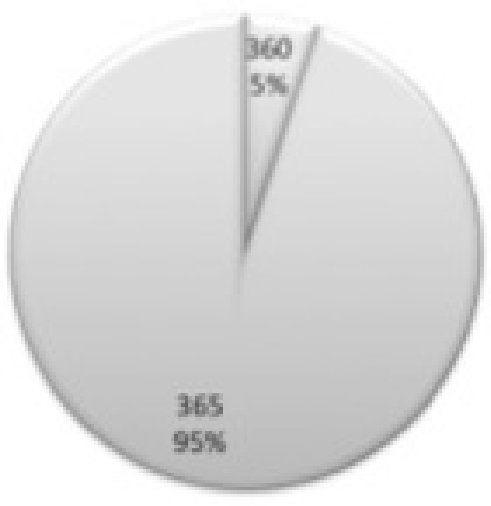

B

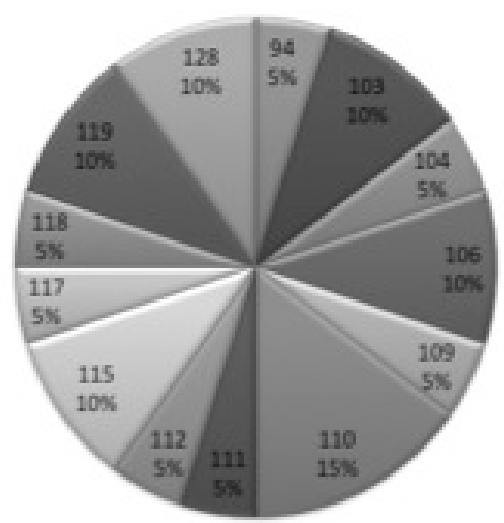

Figure 2. Repartition of the highest and the lowest allele values generated by the species. A. Distribution of the two alleles on Medicago polymorpha using the MTIC354. B. Repartition of the 10 alleles generated by Medicago scutellata using MTIC138.

A maximum of 10 genotypes was observed using the MTIC138 primer for $M$. scutellata. Furthermore, for the most segregating locus, M. scutellata with its 13 obtained alleles was expected to generate more than the 10 genotypes. Only the heterozygous genotype $(234 / / 250)$ was generated by the locus MTIC354 for M. truncatula. This result is illustrated in Figure 3, representing two histograms with the genotype frequencies.

The $N_{\mathrm{A}}$ obtained was higher than the $N_{\mathrm{E}}$ with mean values of 6.738 and 4.841 , respectively. The mean number of $N G_{\mathrm{E}}(18,499)$ was considerably higher than the $N G_{\mathrm{A}}(5.785)$ (Table 4).

The percentage of polymorphism was maximal (100\%) for all species except for $M$. minima. In this case, the transferability did not produce amplification with the MTIC470 primer. The SSR's flanking regions in M. minima can present mutations (In/Dels or SNPs), which prevents the hybridization of this pair of primers. This result agrees with reports of the genera of Vitaceae (Rossetto et al., 2002), which shows highly divergent flanking regions of SSRs. The effectiveness of the selected microsatellite markers to detect molecular polymorphisms demonstrates that they can be used for genetic diversity studies in the Moroccan Medicago phytoresources. 
A

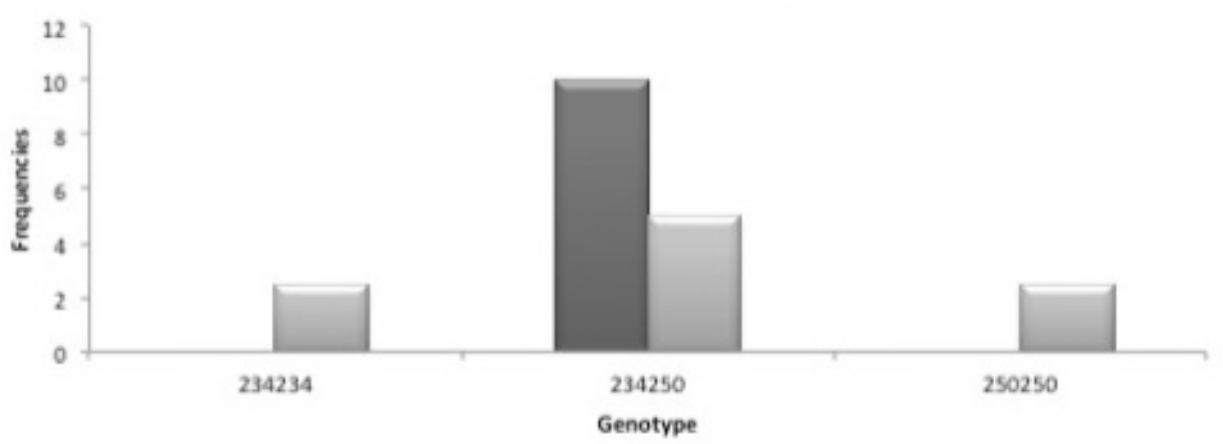

$\mathbf{B}$

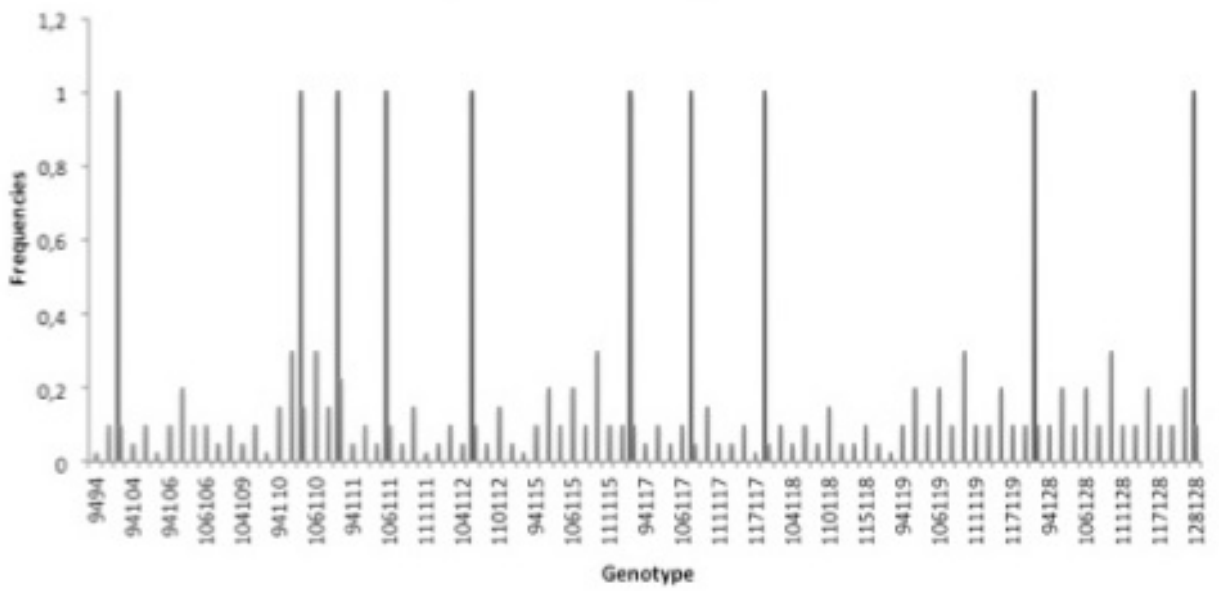

Figure 3. Histograms of the higher and lower numbers of genotypes represented per locus per species. A. Expected versus observed genotypes among Medicago truncatula using MTIC354. B. Expected versus observed genotypes among M. scutellata using MTIC138.

\section{Table 4. Genetic diversity across the six species.}

\begin{tabular}{lcccccccc}
\hline Species & $N_{\mathrm{A}}$ & $N_{\mathrm{E}}$ & $N G_{\mathrm{A}}$ & $N G_{\mathrm{E}}$ & $\% P$ & $H_{\mathrm{O}}$ & $H_{\mathrm{E}}$ & $F$ \\
\hline M. orbicularis & 7.571 & 5.580 & 6.571 & 21.571 & 100 & 0.263 & 0.800 & 0.670 \\
M. polymorpha & 6.000 & 4.045 & 5.571 & 18.714 & 100 & 0.160 & 0.643 & 0.661 \\
M. minima & 6.571 & 4.487 & 6 & 15.571 & 85.71 & 0.330 & 0.671 & 0.536 \\
M. scutellata & 8.000 & 6.372 & 6.142 & 20.714 & 100 & 0.740 & 0.823 & 0.105 \\
M. murex & 6.000 & 4.371 & 4.857 & 15 & 100 & 0.207 & 0.580 & 0.607 \\
M. truncatula & 6.286 & 4.190 & 5.571 & 19.428 & 100 & 0.565 & 0.715 & 0.158 \\
Mean & 6.738 & 4.841 & 5.785 & 18.499 & 97.62 & 0.378 & 0.705 & 0.454 \\
\hline
\end{tabular}

$N_{\mathrm{A}}=$ No. of different alleles; $N_{\mathrm{E}}=$ No. of effective alleles; $N G_{\mathrm{A}}=$ No of different genotypes; $N G_{\mathrm{E}}=$ expected number of genotypes; $\% P=$ percentage of polymorphic loci; $H_{\mathrm{O}}=$ observed heterozygosity; $H_{\mathrm{E}}=$ expected heterozygosity; $F=$ fixation index.

\section{Genetic diversity detected by transferable M. truncatula SSRs}

The $H_{\mathrm{O}}$ was lower than the $H_{\mathrm{E}}$ with averages of 0.705 and 0.278 , respectively. This result suggests a heterozygote deficit. The $H_{\mathrm{O}}$ varied from 0.160 (M. polymorpha) to 0.740 
(M. scutellata), reflecting the high level of polymorphism generated, especially within M. scutellata, which seems to be the most polymorphic. The substantially higher selfing rate in the six medics analyzed might have contributed to a lower overall level of $H_{\mathrm{E}}$. In addition, alleles might have been lost through drift (gene flow) if they are not favored by selection. Furthermore, migrating alleles are especially susceptible to loss through drift in annual species. A low level of heterozygosity was also found for the selfing species M. truncatula in the French Mediterranean region (Bonnin et al., 2001; Ellwood et al., 2006).

$F$ is a measure of the difference between the mean heterozygosity among the subdivisions in a population and the potential frequency of heterozygotes, assuming that all members of the population mix freely and non-assortatively (Hartl and Clark, 1997). $F$ ranges from 0 (indicating no differentiation across the entire population and its subpopulations) to a theoretical maximum of 1 . The mean value of $F$ was 0.454 , which indicates a deficit in the ratio of heterozygotes. This suggests that population subdivision results in a deficit of heterozygosity compared with the expected value under random mating, assuming that the entire population is a single breeding unit. The $F$ values per species were approximately 0.105 and 0.670 for $M$. scutellata and $M$. orbicularis, respectively. This result confirmed that heterozygosity was highest in M. scutellata.

$F_{\mathrm{S}}$ were evaluated for population subdivision as defined by Wright (1965): $F_{\text {IS }}$ (the inbreeding coefficient, which measures the reduction in heterozygosity of an individual due to non-random mating within its subpopulation), $F_{\text {IT }}$ (the overall inbreeding coefficient, which measures the reduction in heterozygosity of an individual relative to the total population), and $F_{\mathrm{ST}}$ (the fixation coefficient, which measures the reduction in heterozygosity of a subpopulation due to random genetic drift). The mean values of $F_{\mathrm{IS}}, F_{\mathrm{IT}}$, and $F_{\mathrm{ST}}$ were $0.452,0.594$, and 0.244 , respectively (Table 5). The intraspecific $F_{\text {IS }}$ variation was more important than the interspecific variation, which reflects the predominantly selfing behavior of Medicago species. Substantial genetic differentiation was found among the six analyzed species, where the $F_{\text {ST }}$ values ranged from 0.137 to 0.451 , indicating a high level of genetic exchange, which might be due to the relative proximity of the geographical areas of the studied accessions or due to human impacts.

\section{Table 5. F-Wright's parameters (1965) and Shannon and Weaver's index (1949) for the 7 SSR primers.}

\begin{tabular}{lcccc}
\hline Locus & $F_{\text {IS }}$ & $F_{\text {IT }}$ & $F_{\text {ST }}$ & $I$ \\
\hline MTIC354 & 0.107 & 0.509 & 0.451 & 3.686 \\
MTIC338 & 0.467 & 0.544 & 0.145 & 4.680 \\
MTIC138 & 0.483 & 0.571 & 0.169 & 4.145 \\
MTIC160 & 0.548 & 0.643 & 0.211 & 4.224 \\
MTIC27 & 0.450 & 0.571 & 0.220 & 4.229 \\
MTIC470 & 0.615 & 0.760 & 0.376 & 4.235 \\
MTIC375 & 0.493 & 0.563 & 0.137 & 4.396 \\
Mean & 0.452 & 0.594 & 0.244 & 4.227 \\
\hline
\end{tabular}

$F_{\text {IS }}=$ intra-specific differentiation; $F_{\text {IT }}=$ total population differentiation; $F_{\mathrm{ST}}=$ inter-specific variation; $I=$ Shannon and Weaver's index.

Accordingly, the $N_{\mathrm{A}}$, the ratio of $N_{\mathrm{E}}$, and $I$ (Shannon and Weaver, 1949) can reflect differences in genetic diversity among species, of which Shannon's information index is an integrated parameter. The average $I$ was 4.227 , with a maximum of 4.680 for MTIC338 and 
a minimum of 3.686 for MTIC354. The locus MTIC338 showed the highest polymorphism, which is in agreement with its higher number of alleles.

Although these species are geographically and, therefore, genetically separated, there was some evidence of positive gene flow between populations of both species and among individuals. A partial exclusion Bayesian-based individual assignment test was used to assess the contemporary rates of genetic exchange between pairs of populations. The $N_{\mathrm{M}}$ matrix (Table 6) demonstrates the relatively high level of pairwise gene flow among the six species. The maximum level of gene flow was found between $M$. scutellata and $M$. orbicularis (2.18), while the minimum was found between $M$. polymorpha and $M$. murex (0.60).

\section{Table 6. Matrix of the pairwise gene flow among Medicago species.}

\begin{tabular}{lcccccc}
\hline & M. orbicularis & M. polymorpha & M. minima & M. scutellata & M. murex & M. truncatula \\
\hline M. orbicularis & 0 & - & - & - & - & - \\
M. polymorpha & 1.37 & 0 & - & - & - \\
M. minima & 1.83 & 1.43 & 0 & - & - & - \\
M. scutellata & 2.18 & 1.03 & 1.91 & 0 & - & - \\
M. murex & 0.86 & 0.60 & 0.87 & 0.88 & 0.61 \\
M. truncatula & 1.28 & 0.78 & 1.12 & 1.29 & 0 \\
\hline
\end{tabular}

\section{Genetic identity and cluster analysis}

Plants and their genes migrate through seed and pollen dispersal. The study of the interplay between seed dispersal and pollination is essential for understanding plant population structure and distribution. In the present study, the genetic identities confirmed the high value of gene flow. Modified from Nei (1972), values ranged from 0.012 for M. murex and M. truncatula to 0.216 for M. orbicularis and M. polymorpha (Table 7). The two assignments (M. orbicularis/polymorpha and M. truncatula/murex) are represented by plots, and show the convergence of the first pair and the divergence of the second pair of species (Figure 4).

\begin{tabular}{|c|c|c|c|c|c|c|}
\hline & M. orbicularis & M. polymorpha & M. minima & M. scutellata & M. murex & M. truncatula \\
\hline M. orbicularis & 1 & - & - & - & - & - \\
\hline M. polymorpha & 0.216 & 1 & - & - & - & - \\
\hline M. minima & 0.093 & 0.215 & 1 & - & - & - \\
\hline M. scutellata & 0.083 & 0.071 & 0.128 & 1 & - & - \\
\hline M. murex & 0.027 & 0.119 & 0.152 & 0.099 & 1 & - \\
\hline M. truncatula & 0.060 & 0.075 & 0.086 & 0.093 & 0.012 & 1 \\
\hline
\end{tabular}

The genetic identity matrix permitted the construction of a UPGMA dendrogram (Figure 5). The dendrogram shows one distinguishable cluster regrouping M. orbicularis and $M$. polymorpha, which are recorded as the most similar species. The UPGMA also revealed significant differentiation of $M$. truncatula from the other five species, suggesting that this species is likely the ancestor of the Medicago genus. The relatively close relationship between $M$. truncatula with both M. scutellata and M. murex is in agreement with previous study based 
on isoenzymatic and plastid trnK/matK analyses (Birouk, 1993; Steele et al., 2010). The relatedness between M. truncatula and M. scutellata was observed on the basis of internal and external transcribed spacers (Bena, 2001). In this study, the segregated SSR markers exhibited the distinctiveness of M. polymorpha and M. murex.

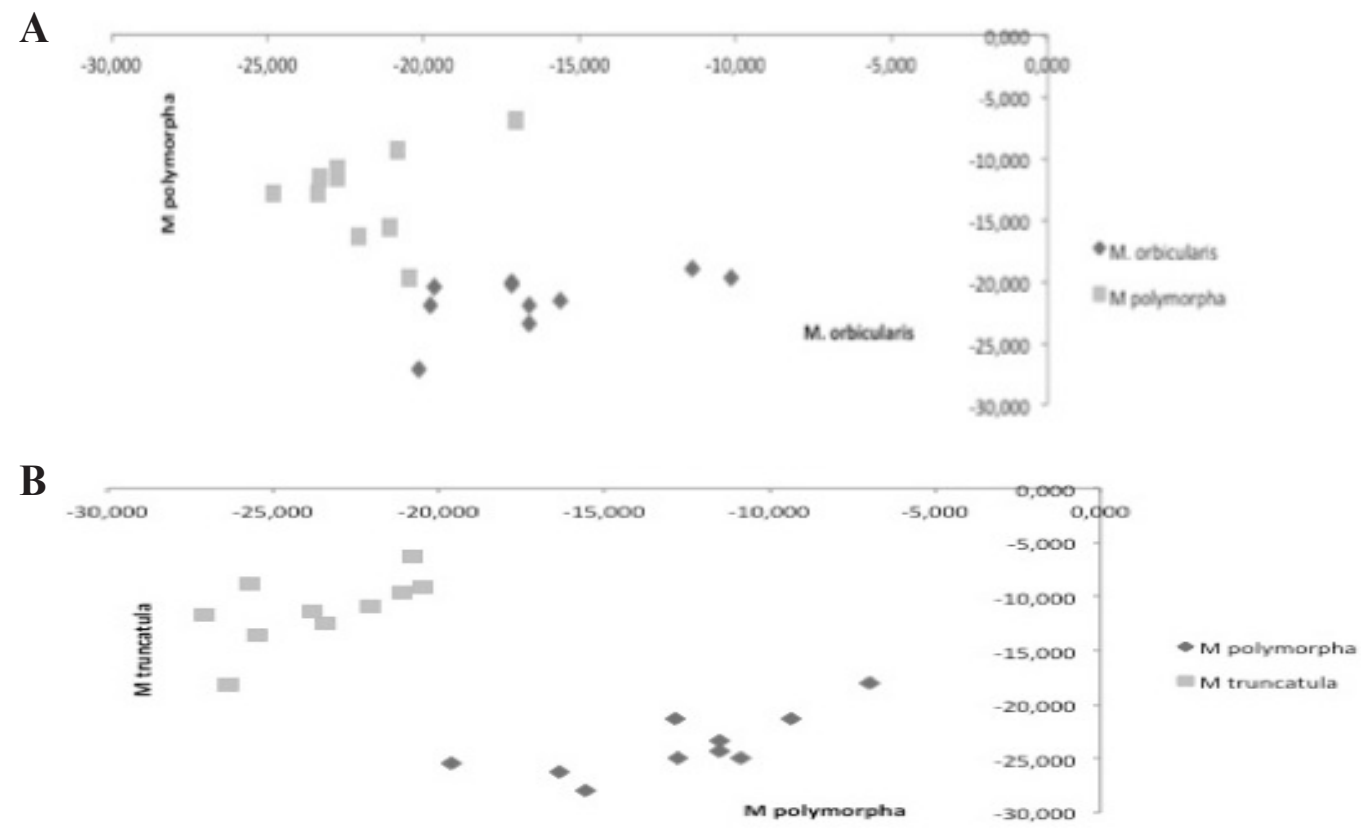

Figure 4. Assignment graphs for the most identic and divergent pairwise species. A. Assignment between the most identic Medicago orbicularis and M. polymorpha species. B. Assignment between the most divergent M. truncatula and M. polymorpha species.

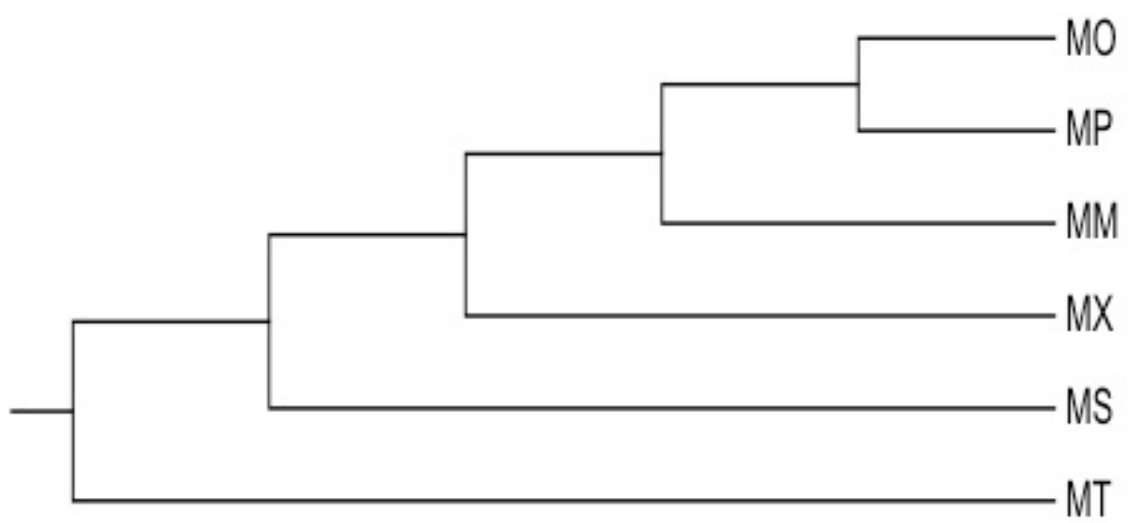

Figure 5. UPGMA dendrogram elaborated with 6 Medicago species elucidating the phylogenetic relationships. $\mathrm{MO}=$ Medicago orbicularis; $\mathrm{MP}=$ M. polymorpha $; \mathrm{MM}=M$. minima $; \mathrm{MX}=M$. murex $; \mathrm{MS}=M$. scutellata; $\mathrm{MT}=$ M. truncatula . 


\section{Correlation between genetic and geographic distances}

Theory suggests that the heterogeneous distribution of genetic variation within and among populations is due to mutation, genetic drift due to finite population size, and heterogeneous natural selection, whereas gene flow and homogeneous directional selection tend to produce genetic homogeneity (Badri et al., 2008). On a broad scale, the factors affecting diversity at the ecological level can also affect or shape genetic differentiation at the molecular level (Tilman, 1999). The correlation between genetic and geographic distances was determined. Based on the latitude and altitude position of each prospected Moroccan station, kilometric distances were obtained (Table 8). Using the Pearson index (r), no significant correlation between genetic and geographic distance was found overall $(\mathrm{r}=0.271, \mathrm{P}=0.322)$. This result suggests that the preferentially autogamous Medicago species are well adapted to their prospected sites in Morocco. These wild species contain a rich source of natural variation that can be used to gain a deeper understanding of plant population dynamics and for the improvement of Medicago species. This result is in line with a phylogenetic study (Ellwood et al., 2006) among M. truncatula's accessions from the SARDI core collection, which also revealed no clear associations between genotype and geographic origin. Ellwood et al. (2006) explained this result based on the nature of the SARDI core, which represents more of an admixture of accessions that were selected for diversity rather than a systematically sampled collection.

\begin{tabular}{|c|c|c|c|c|c|c|}
\hline & M. orbicularis & M. polymorpha & M. minima & M. scutellata & M. murex & M. truncatula \\
\hline M. orbicularis & 0 & - & - & - & - & - \\
\hline M. polymorpha & 57.404 & 0 & - & - & - & - \\
\hline M. minima & 78.210 & 127.089 & 0 & - & - & - \\
\hline M. scutellata & 66.496 & 77.800 & 11.131 & 0 & - & - \\
\hline M. murex & 80.244 & 80.008 & 139.368 & 39.727 & 0 & - \\
\hline M. truncatula & 56.441 & 23.340 & 127.089 & 54.460 & 60.732 & 0 \\
\hline
\end{tabular}

Geographic distances are in kilometer $(\mathrm{km})$.

\section{CONCLUSION}

M. truncatula's SSR markers were found to be highly transferable across five related species, with an amplification efficiency of $97.6 \%$. A total of 283 alleles and 243 genotypes were generated with the seven M. truncatula SSR markers, confirming the high level of polymorphism characterizing Medicago species. In addition, the results showed high intra-specific variation with a heterozygote deficit, and a high level of gene flow among the analyzed species. The preferentially autogamous species and the relative proximity of prospected sites or human impacts reflect the significant genetic differentiation observed. The UPGMA dendrogram generated by the dissimilarity matrix revealed that $M$. polymorpha and $M$. orbicularis are the mostly related species, and that $M$. truncatula appears to be the ancestral species. This study is the first investigation of Moroccan Medicago species, which will be of great interest for amelioration programs of Mediterranean germplasms in light of rapid environmental changes. Furthermore, this study will enable researchers to more efficiently exploit this diversity in order to make informed polymorphic crosses, and to maximize diversity in the collection into a more refined core. 


\section{ACKNOWLEDGMENTS}

Research partially supported by the Tunisian-Moroccan Interuniversity Cooperation Program through project \#25/MT/08. The authors would like to thank Thierry Huguet and Laurant Gentzbittel from the Laboratoire des Interactions Plantes-Microorganismes, Castanet Tolosan cedex, France, for their collaboration in this study by providing the SSR primers.

\section{REFERENCES}

Badri M, Zitoun A, Ilahi H, Huguet T, et al. (2008). Morphological and microsatellite diversity associated with ecological factors in natural populations of Medicago laciniata Mill. (Fabaceae). J. Genet. 87: 241-255.

Belkhir K, Borsa P, Chikhi L, Raufaste N, et al. (2002). GENETIX 4.05, Logiciel sous Windows TM Pour la Génétique des Populations. Laboratoire Génome, Populations, Interactions, CNRS UMR 5000, Université de Montpellier II, Montpellier.

Bena G (2001). Molecular phylogeny supports the morphologically based taxonomic transfer of the "medicagoid" Trigonella species to the genus Medicago L. Plant Syst. Evol. 229: 217-236.

Birouk A (1993). Les Complexes des Medicago au Maroc: Variabilite et Ressources Génétiques. Le Progreès Génétique Passe-il par le Repérage et L'inventaire des Génes? Ed Aupelf-Uref. John Libbey Eurotext Paris, Paris, 307-322.

Bonnin I, Ronfort J, Wozniak F and Olivieri I (2001). Spatial effects and rare outcrossing events in Medicago truncatula (Fabaceae). Mol. Ecol. 10: 1371-1383.

Calonje M, Santiago MB, Dobeš C, Gong W, et al. (2008). Non-coding nuclear DNA markers in phylogenetic reconstruction. Plant Syst. Evol. 282: 257-280.

Chandra A (2011). Use of EST database markers from M. truncatula in the transferability to other forage legumes. $J$. Environmen. Biol. 32: 347-354.

Ellwood SR, D'Souza NK, Kamphuis LG, Burgess TI, et al. (2006). SSR analysis of the Medicago truncatula SARDI core collection reveals substantial diversity and unusual genotype dispersal throughout the Mediterranean basin. Theor. Appl. Genet. 112: 977-983.

Ersts PJ (2010). Geographic Distance Matrix Generator (Version 1.2.3) American Museum of Natural History, Center for Biodiversity and Conservation. Available at [http://biodiversityinformatics.amnh.org/open_source/gdmg]. Accessed November 27, 2011.

Eujayl I, Sledge MK, Wang L, May GD, et al. (2004). Medicago truncatula EST-SSRs reveal cross-species genetic markers for Medicago spp. Theor. Appl. Genet. 108: 414-422.

Gutierrez MV, Vaz Patto MC, Huguet T, Cubero JI, et al. (2005). Cross-species amplification of Medicago truncatula microsatellites across three major pulse crops. Theor. Appl. Genet. 110: 1210-1217.

Haddioui A, Zinelabidine LH, Nouri M, Ajal EA, et al. (2012). Genetic diversity of natural populations of Medicago truncatula in Morocco using isozyme polymorphism. World J. Agric. Sci. 8: 13-19.

Hartl DL and Clark AG (1997). Principles of Population Genetics. 3rd edn. Sinauer Associates, Inc., Sunderland.

Hoshino AA, Bravo JP, Macedo NP and Morelli KA (2012). Microsatellites as tools for genetic diversity analysis. Genet. Divers. Microorganisms 6: 149-170.

Jayashree B, Punna R, Prasad P, Bantte K, et al. (2006). A database of simple sequence repeats from cereal and legume expressed sequence tags mined in silico: survey and evaluation. In Silico Biol. 6: 607-620.

Julier B, Flajoulot S, Barre P, Cardinet G, et al. (2003). Construction of two genetic linkage maps in cultivated tetraploid alfalfa (Medicago sativa) using microsatellite and AFLP markers. BMC Plant Biol. 3: 9.

Lai K, Lorenc MT and Edwards D (2012). Genomic databases for crop improvement. Agronomy 2: 62-73.

Lesins KA and Lesins I (1979). Genus Medicago (Leguminosae), a Taxogenetic Study. Dr. W. Junk Publishers, The Hague.

Lewis G, Schrire B, Mackinder B and Lock M (2005). Legumes of the World. Royal Botanic Gardens, Kew.

Maureira-Butler IJ, Pfeil BE, Muangprom A, Osborn TC, et al. (2008). The reticulate history of Medicago (Fabaceae). Syst. Biol. 57: 466-482.

Nei M (1972). Genetic distance between populations. Am. Nat. 106: 283-292.

Park YJ, Lee JK and Kim NS (2009). Simple Sequence Repeat Polymorphisms (SSRPs) for Evaluation of Molecular Diversity and Germplasm Classification of Minor Crops. Molecules 14: 4546-4569.

Peakall R and Smouse PE (2006). GENALEX 6: genetic analysis in Excel. Population genetic software for teaching and research. Mol. Ecol. Notes 6: 288-295.

Phansak P, Taylor PWJ and Mongkolporn O (2005). Genetic diversity in yardlong bean (Vigna unguiculata ssp. 
sesquipedalis) and related Vigna species using sequence tagged microsatellite site analysis. Sci. Hortic. 106: 137146.

Powell W, Machray GC and Provan J (1996). Polymorphism revealed by simple sequence repeats. Trends Plant Sci. 1: 215-222.

Ronfort J, Bataillon T, Santoni S, Delalande M, et al. (2006). Microsatellite diversity and broad scale geographic structure in a model legume: building a set of nested core collection for studying naturally occurring variation in Medicago truncatula. BMC Plant Biol. 6: 28.

Rossetto M, McNally J and Henry RJ (2002). Evaluating the potential of SSR flanking regions for examining taxonomic relationships in the Vitaceae. Theor. Appl. Genet. 104: 61-66.

Sanders I, Leonid S, Najar FZ and Bruce AR (2011). Wild Crop Relatives: Genomic and Breeding Resources. Legume Crops and Forages, Medicago, 207-222.

Shannon CE and Weaver W (1949). The Mathematical Theory of Communication. University of Illinois Press, Urbana.

Steele KP, Ickert-Bond SM, Zarre S and Wojciechowski MF (2010). Phylogeny and character evolution in Medicago (Leguminosae): Evidence from analyses of plastid trnK/matK and nuclear GA3ox1 sequences. Am. J. Bot. 97 : 1142-1155.

Tamura K, Peterson D, Peterson N, Stecher G, et al. (2011). MEGA5: molecular evolutionary genetics analysis using maximum likelihood, evolutionary distance, and maximum parsimony methods. Mol. Biol. Evol. 28: 2731-2739.

Tilman D (1999). Diversity and production in European grasslands. Science 286: 1099-1100.

Toth G, Gaspari Z and Jurka J (2000). Microsatellites in different eukaryotic genomes: survey and analysis. Genome Res. 10: 967-981.

Varshney RK, Sigmund R, Bornera A, Korzunb V, et al. (2005). Interspecific transferability and comparative mapping of barley EST-SSR markers in wheat, rye and rice. Plant Sci. 168: 195-202.

Wang ML, Gillaspie AG, Newman ML, Dean RE, et al. (2004). Transfer of simple sequence repeat (SSR) markers across the legume family for germplasm characterization and evaluation. Plant Genet. Res. 2: 107-119.

Wright S (1965). The interpretation of population structure by F-statistics with special regard to systems of mating. Evolution 19: 395-420.

Yan J, Chu HJ, Wang HC, Li JQ, et al. (2009). Population genetic structure of two Medicago species shaped by distinct life form, mating system and seed dispersal. Ann. Bot. 103: 825-834.

Yousfi N, Slama I, Ghnaya T, Savoure A, et al. (2010). Effects of water deficit stress on growth, water relations and osmolyte accumulation in Medicago truncatula and M. laciniata populations. C. R. Biol. 333: 205-213. 